\title{
Correction to: Measurement of the ${ }^{15} N /{ }^{14} N$ ratio of phenylalanine in fermentation matrix by isotope ratio mass spectrometry
}

\author{
Shiwei Zhang • Qiding Zhong • Daobing Wang • Zhanbin Huang • \\ Guohui Li
}

Published online: 14 May 2018

(C) Springer Science+Business Media B.V., part of Springer Nature 2018

\section{Correction to: Biotechnol Lett (2017) 39:1853-1857 \\ https://doi.org/10.1007/s10529-017-2387-1}

The publisher was alerted that the following important entry in the references of this article was missing.

\section{Reference}

Broek TAB, Walker BD, Andreasen DH, McCarthy MD (2013) High-precision measurement of phenylalanine $\delta^{15} \mathrm{~N}$ values for environmental samples: a new approach coupling highpressure liquid chromatography purification and elemental analyzer isotope ratio mass spectrometry. Rapid Commun Mass Spectrom 27:2327-2337. https://doi.org/10.1002/ rcm.6695

The original article can be found online at https://doi.org/10.1007/s10529-017-2387-1.

S. Zhang $\cdot$ Z. Huang

School of Chemical \& Environmental Engineering, China

University of Mining and Technology (Beijing),

Beijing 100083, China

S. Zhang · Q. Zhong $(\bowtie) \cdot$ D. Wang · G. Li

China National Institute of Food and Fermentation

Industries, Beijing 100015, China

e-mail: zhongqiding@163.com

S. Zhang · Q. Zhong · D. Wang · G. Li

National Standardization Center of Food \& Fermentation

Industry, Beijing 100015, China 